\title{
The Existence of Housewives in Instagram
}

\author{
Diah Fatma Sjoraida, Rully Khairul Anwar, Edwin Rizal, Diah \\ Sri Rejeki
}

Paper Type:

Research Paper

\section{University of Padjadjaran}

\begin{abstract}
Background of the study: Social media and housewives have become an inseparable unity, especially in Karawang. Accessing social media is a routine that is always done every day. Existence or self-actualization is the reason housewives have social media accounts, one of the Instagram. The purpose of this study is to determine the motives of housewives have Instagram and to know the forms of interaction and content that are distributed to the public.

Purpose: This study aims to determine the impact of the use of Instagram on consumptive behavior of housewives in Karawang.

Method: This qualitative research uses a descriptive method by taking a location on a housewife in Karawang.

Findings: The motive of housewives using Instagram is quite religious, that is entertainment, selling its business, product, socialization, and self-existence, the form of interaction and content distributed in Instagram is post photo with caption interesting, giving hashtag, and follow the trends in Instagram. The conclusion of this research is through Instagram, the housewife can show their existence to the environment to be seen and accepted well.

Conclusion: 1) Instagram is a phenomenal social media among housewives because users are spoiled with various features available on Instagram, 2) the campus provides a large bandwidth so they can access Instagram more easily, and 3) the impact of expanding access to the internet becomes they are more consumptive to do transactions face to face.

Keywords: Instagram, self-existence, housewive, social media
\end{abstract}

Submitted: 30 July 2019 Accepted: 11 April 2020

* Correspondence: Diah Fatma Sjoraida

E-mail: diah.fatma@unpad.ac.id 


\section{Introduction}

Indonesia is one of the countries that diligently visit social media. Noted, at least now there are approximately 130 million people in Indonesia are active in various social media, ranging from Facebook, Instagram, Twitter, and others. In a recent study conducted by We Are Social and Hootsuite, it was revealed that by January 2018, the total population of Indonesia was 265.4 million inhabitants. While the penetration of internet usage reached 132.7 million users. In this data is also seen if approximately 120 million users or roughly 92 percent of the total social media users come from mobile devices. Of course, this amount is an enormous amount (Laksana, 2018). The data shows that social media have had the power to attract Indonesians always to access it.

According to (Nasrullah, 2015), social media is a medium on the internet that allows users to represent themselves as well as interact, work together, share, communicate with other users to form a virtual social bond. In social media, the three forms that refer to the meaning of personal are cognized, communicate and cooperate. Meanwhile, according to Puntoadi (2011), social media begins with sharing, collaborating and connecting. This means that social media is a place to share information, cooperation and liaison between one party with other parties.

According to Nasrullah (2015) states, there are six broad categories of social media distribution, namely:

1. Social networking. Each user establishes a network of friends, both to users who already know and possibly meet each other in the real world and form a new system of friends. Examples of social networking that is widely used are Facebook and LinkedIn.

2. Online journal (blog). The blog is a social media that allows users to upload daily activities, mutually commenting and sharing, both other web links, information, and so forth. At first, a blog is a form of a personal site that contains a collection of links to other sites that are considered attractive and updated every day. In further developments, many blog journals (own daily writing) media owners and there is a comment column that can be filled by the user. Example wordpress.com, thumblr.com, blogspot.com, or use your domain.

3. Microblogy. is a type of social media that facilitates users to write and publish their activities and opinions. The most popular example is Twitter.

4. Media sharing. Media sharing sites are a type of social media that facilitates their users to share media, from documents (files), video, audio, images, and so on. Examples of this media are YouTube, Flickr, Photo-bucket, path, or Instagram.

5. Social bookmarking. Social media were working to organize, store, manage and search for specific information or the news online. Some of the popular social bookmarking sites are delicious.com, stumbleUpon.com, Digg.com, Reddit.com, and for Indonesia there is LintasMe.

6. Media shared content or wiki. Social media is a site whose content is the result of collaboration from its users. Similar to dictionaries or encyclopedias, wikis present to users the understanding, history of book references or links about a single word. In practice, the explanations are made by visitors, meaning there is a collaboration or cooperation of all visitors to fill the content in this site.

One of the social media that is used by many gadget users today is Instagram. The internet, social media and social networking are indeed bringing change to the world, but still, besides positive impacts are sure to be accompanied by adverse effects. Many Instagram users aim to express their personalities through Instagram social media, one of which is to fulfill his pleasure and satisfaction through uploaded photos (Pittman \& Reich, 2016). Regarding uploading photos on Instagram can give freedom of expression to meet its satisfaction. Instagram is a photo-sharing app that lets users take pictures, apply digital filters, and share them with various social networking services, including Instagram's own. Instagram stood in 2010 and was founded by two friends Kevin Systrom and Mike Krieger (Mahendra, 2017). The general purpose of Instagram itself one of them that is as a means of the penchant of each who wants to publish activities, goods, places or even himself into the form of photos. It becomes interesting if it is related to the concept of housewive existence on Instagram, the 
reason why housewives use Instagram, how the type of interaction is done, what content is usually distributed, and others.

Housewives are known for the stereotype of unemployed women because they are considered not to have professions that generate material profits. The housewife can be interpreted as a woman who organizes the implementation of various household chores or not working in the office (Junaidi, 2017). Life of housewives who does the same thing with repeatedly (routine) will experience the symptoms of stress, let alone the housewife had previously been working in the office. The trigger of housewives to stress is feeling lonely, including because they rarely communicate and interact with their friends and explore the existence of him that gradually disappears. Therefore, housewives try to eliminate the stress trigger by doing activities in social media, especially Instagram. When the activity they build is a good creative activity and can produce a lot of work of housewives gain a positive existence of themselves to the social environment. Unlike if housewives are doing the opposite action, provide a work that aims to show off, arrogant, vilify others or even for criminal matters (Radovic, Gmelin, Stein, \& Miller, 2017).

Previous research conducted by Aziz Hakim (2015) explains that households use social media or social networks to fulfill their pleasure, one of which is fulfilling their sense of self-existence and entertainment when they feel fed up with their routine. The presence of social media is increasingly needed in everyday life even though it can eliminate the limitations in interacting, where social media is created without any space and time restrictions that prevent anyone from communicating so as to have a great influence on the social lives of its users. BBC Future (2018) examines some of the effects arising from most social media, such as Facebook, Instagram, Twitter and others that have an impact on mental health, including In 2015, researchers at the Washington-based Pew Research Center found how social media can cause stress and not reduce it. In the study, a survey involving 1,800 people was conducted, and the results showed that women were more prone to stress than men. Twitter is said to be an "important contributor" because it increases their awareness of the pressures experienced by others. But Twitter also acts as a coping mechanism, and the more women use it, the less stress they have. But the same effect was not found in men, and the researchers mentioned that more had distanced relations with social media. Overall, the researchers concluded that social media use was associated with stress "to a lesser extent."

It is furthermore related to mood. A researcher from Austria In 2014, stated that the mood of the respondents decreased or lower after using Facebook for 20 minutes when compared with those who only surfed on the internet. From the results of these studies show that someone can feel it because they see things that waste time. More than that, a good or bad mood that someone feels can be contagious or spread to other users of social media. A researcher from the University of California, assessed if the emotional content of more than one billion status uploads from more than 100 million Facebook users from 2009 to 2012. The effect of bad weather can also increase the negative change by $1 \%$, and the researchers found that with a negative upload someone in cities that are often washed down rain affects 1.3 million other negative uploads from people who live in the hot cities. Another thing that is good news is that positive and happy posts have a stronger influence and can inspire more than 1.75 other cheerful posts.

The researchers examined the anxiety that arises due to social media. Anxiety caused by social media is characterized by feelings of anxiety and excessive worry, often causing a person difficult to sleep and difficult to concentrate. In the journal Computers and Human Behavior revealed that people who use more than seven types of social media have a three times higher chance of experiencing anxiety when compared with those who use two social media. There is no clear clarity about how social media can cause anxiety. A researcher from Babes-Bolyai University in Romania reviewed a previous study of the relationship between social anxiety and social networking in 2016 with mixed results. Some conclusions require further research on this matter.

Depression became the most part in various studies. There are researchers who have managed to find a link between depression and the use of social media, the research is developing also about 
how social media can really be a tool for good intentions and goals. There are two studies involving as many as 700 students who experience symptoms of depression, including chaotic moods, feelings of lack of enthusiasm, loss of hope, and severe turmoil associated with the quality of online interactions. The researchers found higher depressive symptoms related to the quality of their online interactions. Another similar study was conducted in 2016 and involved as many as 1700 people with the following results: the risk of depression and anxiety tripled among the people who used the most social media, known to be the cause of their negative thinking, including cyber abuse, had views distorted about the lives of others and feeling that spending time surfing the internet is a waste of time.

A large number of housewives who use Instagram, of course, raises the opportunity to optimize the presence of social media as a venue for existence, so that then raises the question, how the life of housewives in social media Instagram.

\section{Research Method}

The research located in West Karawang uses qualitative (Moleong, 1999) defines that qualitative research is scientific research, which aims to understand a phenomenon in a natural social context by emphasizing the process of a deep communication interaction between researchers with the events studied. The informant in this research is a housewife who uses Instagram regularly.

Data collection and processing techniques in qualitative research can be done in various forms, namely through 1) Observation. This technique is used to obtain information or precise information about problems related to the existence of housewives on Instagram. In this case, the researchers directly plunge spaciousness to perform data collection. In this regard, researchers directly go to the field to collect data. The writer interacts with at least 3 active housewives who use Instagram. 2) Interview. Researcher to conduct interviews with key informants through interviews that are natural, but still structured according to the patterns of the interview conducted by researcher activities. Based Interview with key informant, i.e., researcher conducted the free interview, but structured by the pattern of transcripts that researchers submitted in research activities. Interview techniques are researchers approaching and adapting for information. When the writer gets a lot of information from information related sources, information will be filtered (setting) to obtain information researchers will be able to interview directly. 3) Documentary Study. In the determination of document studies, it is done through literature book, books or previous research results.

The data analysis technique used in this research is based on qualitative research which is commonly used by every researcher, therefore the writer takes the guidance developed by qualitative researchers, that is based on the concept built by Miles \& Huberman (2013) by using the 3 phase model, IE, data collection, data reduction, data presentation, and conclusions.

\section{Result and Discussion}

Instagram's success as a photo-sharing service has its charm, making Facebook spend the US $\$ 1$ billion in cash and stock to acquire it in 2012. In 2010, Kevin Systrom and other Instagram founders Mike Krieger quickly realized that something a big one will happen. That's because everyone is seen carrying a phone that has a camera. They say that in the future photos will be one powerful communication tool (Librianty, 2015). Formerly Instagram is not as popular nowadays; it is caused by problems such as most applications in Internet network so slow that Systrom and Krieger try hard to ensure that photos uploaded can be efficient that is in a small square.

Another problem is that many people want to share their pictures with many different networks. Until finally, the founders made a feature that allows everyone with different systems, sharing their photos with just a push of a button. The last problem is about one of the reasons people do not take pictures. The idea was because of the quality of the photo when it was not so good. This is what lies behind the birth of filters on Instagram. Currently, all Instagram users can easily snapshot, 
edit and upload their photos with confidence.

Instagram even has the latest features that can threaten other applications, such as (1) video chat that can accommodate two to four people, including the caller in a chat room, (2) topic channels in explores the user can more easily find content preferably categorized. Like the music, comic, travel or other material that is claimed to be sorted based on user preferences, (3) filter effects and AR stickers. With some partners like pop singer Ariana Grande, BuzzFeed, Baby Ariel, Liz Koshy, and NBA, Instagram releases camera effects as features typical of these partners. If you follow one of these partner accounts, the camera effects will appear in the Instagram Stories option, either a 2D or augmented reality (AR) filter, (4) Instagram also brings shopping feature to Instagram Stories early June. In this feature, brands like Adidas, to Louis Vuitton can showcase their product catalog and put a shopping bag sticker. By clicking Shopping Bag, users will be given information about the selected product and can directly buy it via stories. Again, this feature is similar to the Shoppable AR feature in Snapchat released last April. (5) IG TV This application is made separately, but still can be accessed from the main application. IGTV will be the competitor of today's most popular video-sharing platform, YouTube. (6) Not only does it duplicate Snapchat and YouTube features, but Instagram also carries the primary function of a favorite question and answer app, ask.fm. Instagram takes the ask.fm scheme to the "question" feature that can be embedded in Instagram Stories. During this time, users can only ask open questions through two choices of answers that appear in the options sticker. A few days launched, this feature seems quite a lot of demand for Instagram users. Users can throw questions to followers in the "ask me something" column, then their followers can respond in the "type something" field. Regarding business, this feature is fascinating to read the response of its customers (Pertiwi, 2018).

Currently, Instagram is one of the social media that is widely used in the community, both young and adults, both used for personal needs as well as business needs they live. Instagram is a photo-sharing app that lets users take photos, apply digital filters, and share them with various social networking services, including Instagram's own. Its presence makes people competing to produce the best pictures and upload photos. Not only that. Instagram becomes a means of business, advertising and as a place to show off. Many accounts have uploaded images on vacation somewhere, beautiful nature photos and deliberately uploaded photos to let you know that the account owner once went to the place. So many images are taken from the same spot to get the recognition that the account owner is not considered out of date.

\section{Motives of Housewives Use Instagram}

The humanistic psychologist, Abraham Maslow, mentions that man has five basic needs that form the stages of physiological, security and safety, social, appreciation, and self-actualization. Physiological needs include clothing, food, and individual boards. Security and safety needs are essential because human life wants security and is protected from dangerous people and pain. Once the needs of security are met, then the social needs of trust, love, compassion, are also needed by humans (Deutsch, 1975). Because of social life, an individual needs a relationship with others and will try to be accepted into a group (Hopwood, Mellor, \& O'Brien, 2005). Once the social needs are met, then comes the need for appreciation or coveting. Maslow assumes that humans want to get the praise, recognition, and attention of those around him. For example, homemakers who already have Instagram accounts, of course also try to have a lot of followers or followers and no less important is the number of like on the uploaded photos. That way the account owner feels recognized by his followers. Do not stop there, the majority of owners of other Instagram account follow-up upload photos in the same place, or most of them will go to the area, take pictures and upload it on Instagram. Then comes the need for self-actualization. This need is a need to realize the ability of a person to be able to recognize the self-image. Instagram has now become a means of forming a self-image for its users. Many do not want to lose for continually traveling to be considered as a wealthy person who has the opportunity to go wherever he wants. 
Motives housewife owns and uses Instagram account is for entertainment, to socialize and to show the real identity. Based on interviews, one housewife wants to show her harmonious private life to the public to be a source of inspiration for others. But there are also housewives who deliberately want to show a life that is now better than before. For example, once did not have a car, now has a car by uploading a photo of yourself with a new car on Instagram. That is, existence explains about the assessment of the existence or absence of influence on the existence of a person. What housewives do is show their existence to be seen by others.

Besides, most housewives have 2 Instagrams accounts, consisting of the original Instagram that shows the social life that a person desires with a fake Instagram account whose function is to comment on someone else's Instagram account or to stalk the people of the day then. Other than that housewives use Instagram for fun, which includes the fulfillment of self-existence for the user and entertainment when they feel saturated with everyday life.

\section{Interaction and contents in Instagram}

Many people today are using social media as a platform to show themselves to the outside world. Everyone is competing to showcase and branding about himself to the outside world. Through various photos, videos, statements that are on social media, someone wants to reveal to others that this is her. Not infrequently also even someone can act excessively to show their existence to others (Chaniago, 2017). Based on the results of research, recorded content-content that is usually uploaded by housewives as a means of self-actualization, among others:

1. Selfie. Shows photos of yourself with the best performances, such as photos after makeup, photos wearing new clothes, pictures with new looks or pictures when feeling beautiful. In this selfie housewife sometimes uses the filter contained in the Instagram facility for the results are satisfactory. The most commonly used filter example is a filter that works to brighten up the photo. The housewives will feel happy and proud if there is a person or follower who pressed the "like" or comment on the picture.

2. Culinary. Shows photos of food either result of buying or making your own. But the majority of housewives upload pictures of the purchase, especially if the food is unique, luxurious and obtained from the famous place. Usually, for photos of their dishes include hashtags that match the name of the meal. For example \#baksomalang, \#harvest, and others.

3. Family. Shows photos of the family, usually the majority of housewives upload pictures of their children's activities equipped with cute captions about the child.

4. Quotes. Housewives sometimes upload pictures of quote-quote that can inspire their follower, not infrequently they upload the quote tailored to their life story.

5. Traveling. Many housewives upload photos that are going to specific tourist attractions with a caption that is persuasive and hashtag name of the tourist location.

6. New things and expensive things. There are also housewives who upload photos of new items bought at a price that is expensive, such as branded watches, branded luxury bags, new motorcycles, new cars, and others. Usually, the photo of the new items comes with thanksgiving, thanks to the person who has presented the gift.

Everyone has different attributes and thoughts, as well as life plans, have different goals. The level of each need there who already feel entirely only to the degree of social needs where he felt enough to be loved and loved the people around him. But there is also not enough just to the level of social needs, and there must be recognition from others to increase his self-esteem. Smith (Lenhart,A., Purcell, K, Smith A, ., Zickuhr, 2010) said Self Existence is a condition in which a person with the ability to find meaning in life. Eating is a fulfillment or the existence of the ultimate virtuous values in living life. The inner values that were discussed are fundamental values such as respect for human beings, respect for others and the need to cooperate and work together in harmony for the common good. The forms of interaction performed by the housewives are one way for the existence of self to be seen and accepted by the environment well. 
The difference between this research and previous research lies in the form of interaction carried out by housewives in their existence. In previous studies, self-existence was carried out with housewives who always commented on photos/videos posted by others, while in this study the focus was on sharing the events that had been experienced by the informant.

\section{Conclusion}

Based on the results of research on the existence of housewives in Instagram, that Instagram can be a medium for housewives who want to show their presence through uploaded photos, captions of interest, and hashtag following the trend. Suggestions in this study are to be more careful with uploading pictures because there are a few dangerous people who will use the information from the post. Housewives should be trained on media literacy to use social media wisely.

\section{Acknowledgment}

The authors would like to say thank you to the Rector of UNPAD, Research Director UNPAD, Dean of Faculty of Communication Science UNPAD who has given the opportunity to conduct this research. The highest appreciation we also convey to the housewives of West Karawang, and West Java, Indonesia.

\section{References}

Chaniago, R.. (2017). Selfie Sebagai Wujud Meningkatkan Eksistensi Diri Mahasiswi Melalui Akun Instagram (Studi Kasus Mahasiswi Bimbingan Konseling Islam IAIN Purwokerto Tahun 2014). IAIN Purwokerto.

Deutsch, M. (1975). Equity, equality, and need: What determines which value will be used as the basis of distributive justice? Journal of Social Issues, 31(3), 137-149.

Hopwood, B., Mellor, M., \& O’Brien, G. (2005). Sustainable development: mapping different approaches. Sustainable Development, $\quad 13(1), \quad 38-52$. https://doi.org/https://doi.org/10.1002/sd.244

Junaidi, H. (2017). Ibu Rumah Tangga: Streotype Perempuan Pengangguran. An Nisa'a, 12(1), 7788.

Laksana, N. C. (2018, March). Ini Jumlah Total Pengguna Media Sosial di Indonesia. Okezone.Com.

Lenhart,A., Purcell K, Smith A, ., Zickuhr, K. (2010). Social Media and Young Adults. Pew Internet \& American Life Project.

Librianty, A. (2015). Melongok Sejarah Instagram 5 Tahun Lalu. Liputan6.Com.

Mahendra, B. (2017). Eksistensi Sosial Remaja dalam Instagram (Sebuah Perspektif Komunikasi). Markerting Communications Garda Perdana Security, 16(156), 151-160.

Matthew B. Miles, \& Huberman, A. M. (2013). Qualitative Data Analysis: An Expanded Sourcebook. London and New Delhi: Sage Publications, Inc.

Moleong, L. J. (1999). Metodologi Penelitian Kualitatif. Bandung: Rosda Karya.

Nasrullah, R. (2015). Media Sosial Perspektif Komunikasi, Budaya dan Sosioteknologi.

Pertiwi, W. N. . (2018). 7 Fitur Baru Instagram Ancam Snapchat, YouTube, dan Ask.fm.

Pittman, M., \& Reich, B. (2016). Social media and loneliness: Why an Instagram picture may be worth more than a thousand Twitter words. Computers in Human Behavior, 62, 155-167. https://doi.org/10.1016/j.chb.2016.03.084

Puntoadi. (2011). Menciptakan Penjualan Melalui Social Media. Jakarta:

Radovic, A., Gmelin, T., Stein, B. D., \& Miller, E. (2017). Depressed adolescents' positive and negative use of social media. Journal of Adolescence, 55, 5-15.

Smith, W . H. (2003). What Matters Most: Hal-Hal Yang Paling Utama. Jakarta: Bina Rupa Aksara. 